\title{
Hypertensive Disorders of Pregnancy and Risk of Cardiovascular Disease-Related Morbidity and Mortality: A Systematic Review and Meta-Analysis
}

\author{
Rong Wu ${ }^{a}$ Tingting Wang ${ }^{a}$ Runhui Gu ${ }^{b}$ Dexiu Xing ${ }^{a} \quad$ Changxiang Ye ${ }^{a}$ \\ Yan Chen ${ }^{\mathrm{a}}$ Xiaoling Liu ${ }^{\mathrm{a}}$ Lizhang Chen ${ }^{\mathrm{a}}$ \\ a Department of Epidemiology and Health Statistics, Xiangya School of Public Health, Central South University, \\ Hunan, China; ${ }^{\mathrm{b}}$ School of Public Health, Nanjing Medical University, Jiangsu, China
}

\section{Keywords}

Hypertensive disorders of pregnancy · Gestational

hypertension · Preeclampsia · Cardiovascular disease ·

Hypertension · Death

\begin{abstract}
Introduction: Several studies have demonstrated that there is a higher risk of cardiovascular disease (CVD) in women with a history of hypertensive disorders of pregnancy (HDP). However, effect sizes varied greatly between these studies, and a complete overview of the existing data in the literature is lacking. We aimed to evaluate the association between HDP and the risk of CVD-related morbidity and mortality. Methods: Systematic literature searches were conducted in several electronic databases from inception to July 2019. Exposure of interest was any type of HDP. Outcomes of interest included any CVD, CVD-related mortality, and hypertension. Results: Sixty-six cohort and 7 case-control studies involving $>13$ million women were included. The overall combined relative risks (RRs) for women with a history of HDP compared with the reference group were 1.80 (95\% confidence interval [CI] 1.67-1.94) for any CVD, 1.66 (1.49-1.84) for coronary artery heart disease, 2.87 (2.14-3.85) for heart failure, 1.60 (1.29-2.00) for peripheral vascular disease, 1.72 (1.50-
\end{abstract}

karger@karger.com

(c) 2020 S. Karger AG, Basel

www.karger.com/crd

Karger!
1.97) for stroke, 1.78 (1.58-2.00) for CVD-related mortality, and 3.16 (2.74-3.64) for hypertension. Significant heterogeneity was partially explained by all or part of the variables including type of exposure, follow-up time, geographic region, and sample source. Conclusions: Women with a history of HDP are at an increased risk of future CVD-related morbidity and mortality. Our study highlights the importance of life-long monitoring of cardiovascular risk factors in women with a history of HDP.

(c) 2020 S. Karger AG, Basel

\section{Introduction}

Approximately $15 \%$ of parous women have at least 1 pregnancy complicated by a hypertensive disorder [1]. As reported, hypertensive disorders of pregnancy (HDP) are associated with maternal and fetal complications [2-7]. Given that approximately 30,000 maternal and 500,000 perinatal deaths annually can be attributed to HDP, these disorders have been regarded as one of the major contributors to maternal and fetal mortality and morbidity globally [8-10].

L.C. and T.W. are both corresponding authors. 
Historically, HDP were considered to be self-limiting and have little long-term effect on health since the blood pressure of most of the women affected would return to normal within 12 weeks after delivery [11]. However, residual anomalies and increased cardiovascular disease (CVD) risk factors (e.g., hypertension and diabetes) in women with a history of HDP are likely to render these people becoming increasingly at risk of developing CVD $[12,13]$. Interest in testing this hypothesis has grown rapidly in the past years. However, no consensus has been reached even today. Several studies have reported a significantly higher risk of composite cardiovascular events in women with a history of HDP compared with a reference group [14, 15], but others have not found a significant association between HDP and a long-term risk of developing CVD $[16,17]$. Notably, even in studies providing a supportive evidence, effect sizes varied greatly. Given the increasing prevalence of HDP, it is necessary to summarize the existing evidence of the association of HDP with long-term CVD-related morbidity and mortality through integrated approaches.

To this end, our objective here was to perform an updated meta-analysis regarding the association between HDP and the risk of developing CVD-related morbidity and mortality. Our results may lead to a better understanding of CVD risk in women with HDP, which will help to guide future management and contribute to guidelines for clinicians.

\section{Methods}

\section{Search Strategy}

This systematic review was conducted following the proposed Systematic Reviews and Meta-Analyses (PRISMA) [18] and the Meta-Analysis of Observational Studies in Epidemiology (MOOSE) [19] reporting guidelines.

Two authors independently identified observational studies published in English prior to 8 July 2019 and reported data on cardiovascular outcomes in women with and without HDP. PubMed, Embase, and Web of Science were systematically searched. The search terms used in combination were: (1) pregnancy, pregnant, gestational, gestation, hypertensive, hypertension, pre-eclampsia (PE), preeclampsia, eclampsia, edema-proteinuria-hypertension gestosis, toxemia of pregnancy, and hemolysis-elevated liver enzymes-low platelets (HELLP) syndrome; and (2) cardiovascular diseases, CVD, coronary disease, coronary thrombosis, coronary stenosis, coronary restenosis, coronary artery disease, coronary heart disease, acute coronary syndrome, ischemic heart disease, myocardial ischemia, myocardial infarction; heart failure, cardiac failure, left ventricular systolic dysfunction, cardiomyopathy, peripheral vascular disease, pulmonary embolism, venous thromboembolism, deep vein thrombosis, cerebrovascular disorders, cerebrovascular disease, cerebrovascular accident, stroke, death, and mortality. In addition, the reviewers manually searched the reference lists of the articles selected to identify any relevant studies missed in the initial search.

\section{Exposure and Outcomes}

The exposure of interest was any type of HDP, including gestational hypertension (GH), PE, eclampsia, HELLP syndrome, and chronic hypertension with superimposed PE. Primary outcomes included any type of CVD and CVD-related mortality. CVD was defined as any of the following events: coronary artery heart disease, heart failure, peripheral vascular disease, and stroke. Coronary artery heart disease included coronary heart disease, ischemic heart disease, myocardial infarction, and coronary artery disease. Peripheral vascular disease was defined as peripheral arterial disease, deep vein thrombosis, and any thromboembolic events. Stroke was defined as any composite stroke, stroke unspecified, and stroke/transient ischemic attack. The outcome CVD-related mortality was defined as death due to any CVD. Although hypertension is outside the range of CVD, we included hypertension as the secondary outcome given its importance as a risk factor for CVD.

\section{Study Selection}

At the title and abstract screening stage, we purposely broadened the inclusion criteria to obtain all relevant studies. Studies were considered for inclusion if they were published in English and reported on CVD, CVD-related mortality, and hypertension among women with HDP. The full texts of all selected studies were then reviewed. Studies were included if they (1) were original articles, (2) included at least 2 groups (1 with HDP and 1 without HDP), (3) provided sufficient information to allow for accurate risk estimates to be calculated, and (4) the full-length article was available. Conversely, studies were excluded if they (1) were review papers, conference abstracts, case reports, experimental studies, or qualitative studies, (2) had incomplete or unclear data, or (3) were duplicate publications. There was no restriction based on cohort type, study design, or duration of follow-up. When there was $>1$ study that involved the same population of HDP patients, only the most recent published or comprehensive one was included.

\section{Data Extraction}

Two reviewers independently extracted and evaluated the data for each included article using a self-designed data abstraction form. Disagreements were resolved through discussion or consultation with a third reviewer when consensus could not be achieved. The following data were extracted: first author, year of publication, geographic region, study period, sample source (population- or hospital-based), type of exposure (HDP, GH, PE, eclampsia, HELLP syndrome, or chronic hypertension with superimposed $\mathrm{PE}$ ), any adjustments or matches made, sample size, mean age, reported outcomes, and risk estimates with $95 \%$ confidence intervals (CIs; the adjusted ones were collected when available). In cohort studies, the duration of follow-up was also extracted.

\section{Study Quality Assessments}

The methodological quality of studies was assessed using the Newcastle-Ottawa Scale (NOS) for quality assessment of cohort and case-control studies by 2 researchers (R.W. and T.W.) independently. The NOS was composed of 8 items. It ranged from 1-9 stars and assessed the quality of each study based on 3 modules: 


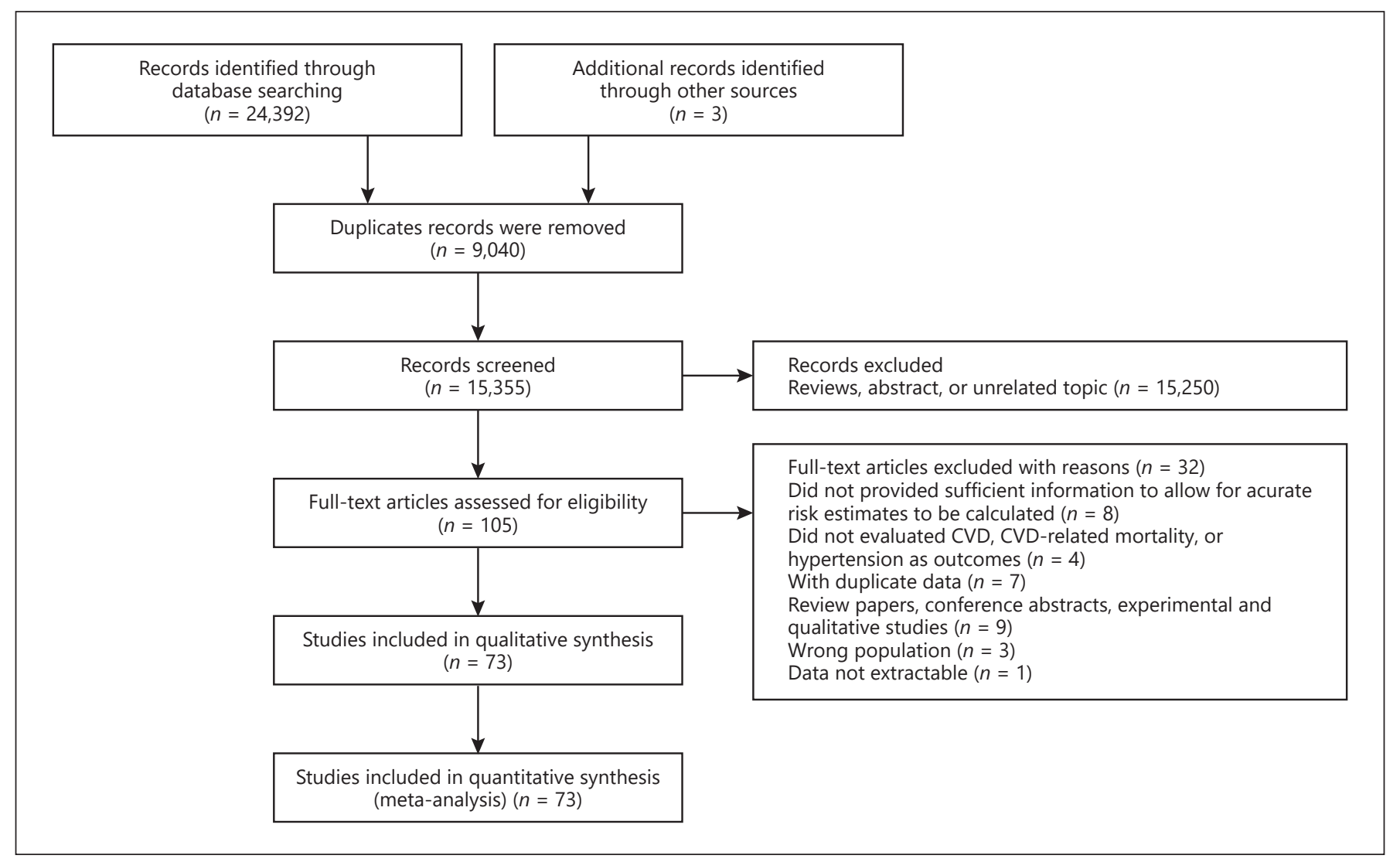

Fig. 1. Flow chart of study selection.

selection, comparability, and outcome (cohort studies) or exposure (case-control studies). A final median score of $\geq 6$ was regarded as high quality.

\section{Statistical Analyses}

The risk ratio (RR) was used as the measure of the association between the history of HDP and a risk of any CVD, coronary artery heart disease, heart failure, peripheral vascular disease, stroke, CVD-related mortality, and hypertension. The hazard ratios (HRs) and odds ratios (ORs) were directly considered as RRs.

RevMan v5.3 (Nordic Cochrane Center) and Comprehensive Meta-Analysis v2.2 were used to perform all analyses in this study. The Cochran Q test and the $I^{2}$ statistic were used to assess the heterogeneity of RRs across studies. The Cochran Q test was used to evaluate whether the variation across studies was compatible with chance, and $p<0.1$ was considered to indicate significant heterogeneity. The $I^{2}$ statistic was a quantitative indicator used to evaluate the percentage of total variance in risk estimates due to statistical heterogeneity rather than chance, or sampling error $\left(I^{2}>75 \%\right.$, high heterogeneity; $51-75 \%$, substantial heterogeneity; $26-50 \%$, moderate heterogeneity; $\leq 25 \%$, low heterogeneity). The pooled RRs and 95\% CIs were calculated using random-effects meta-analyses. To explore possible sources of heterogeneity, subgroup analyses were performed according to geographic region (Asia vs. Europe vs. North America), sample source (hospital-based vs. popu- lation-based), type of exposure ( $\mathrm{GH}$ vs. $\mathrm{PE}$ ), whether the confounders were adjusted (adjusted vs. unadjusted), and median/ mean follow-up time ( $\leq 10$ vs. $10-20$ vs. $\geq 20$ years). Then, a $Q$ test for heterogeneity was used to compare the subgroup differences under the random-effects model (here, $Q$ would be distributed as $\chi^{2}$ with $\mathrm{df}=1$ and $p<0.05$ indicating statistically significant differences) [20].

Sensitivity analysis was conducted to examine the influence of individual studies on the overall RRs by repeating the meta-analysis after the exclusion of each included study. Sensitivity analyses were also performed to examine the influence of case-control studies on the overall RRs. Publication bias was evaluated using Begg's test $(p<0.05$ indicated statistically significant differences).

\section{Results}

\section{Identification and Characteristics of Studies}

In total, 24,395 unique citations were identified after an initial search. Of these, 24,290 were excluded after screening titles and abstracts, mainly because they were duplications, reviews, or not related to our study (Fig. 1). Then, the full texts of 105 articles were reviewed; a total 


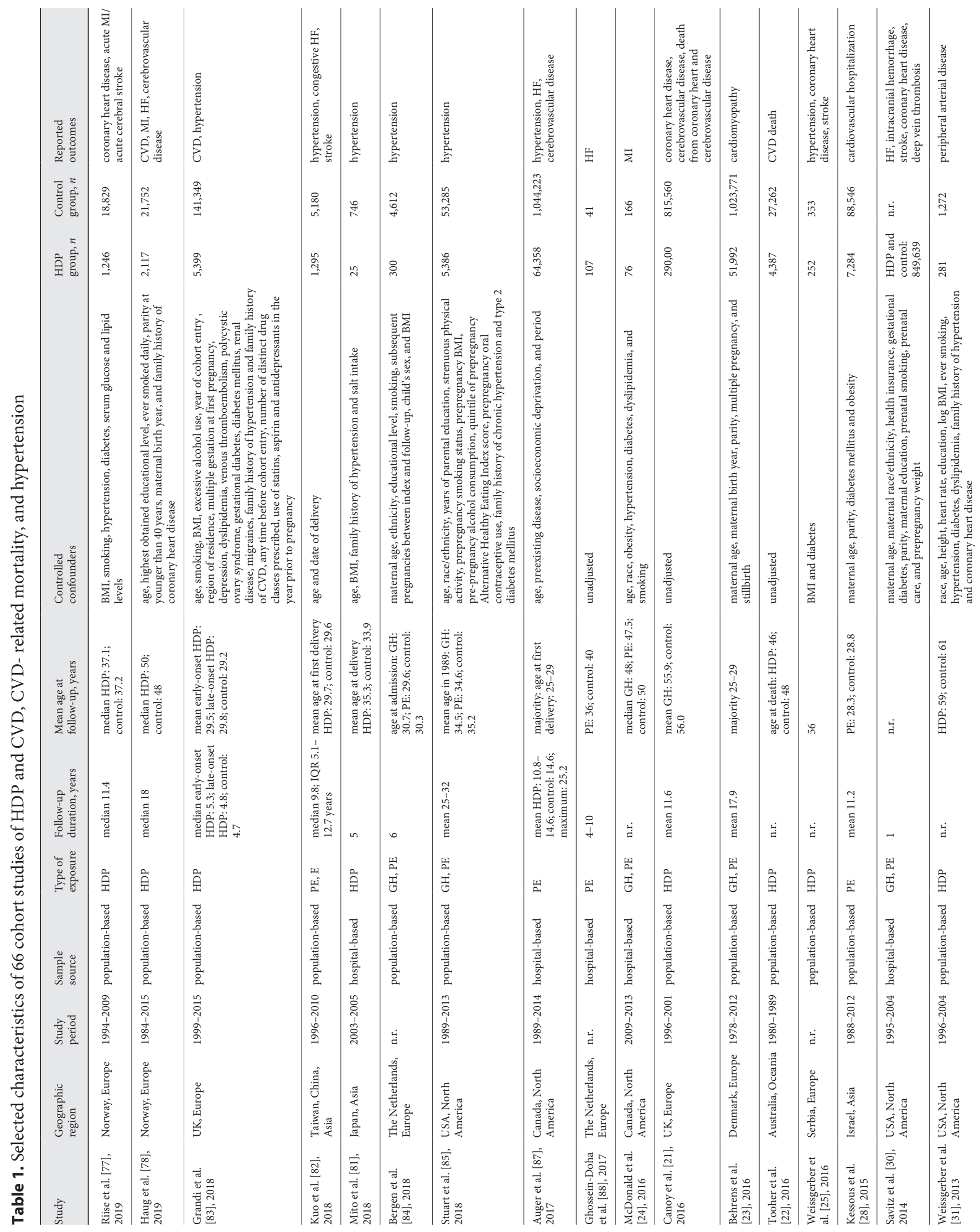




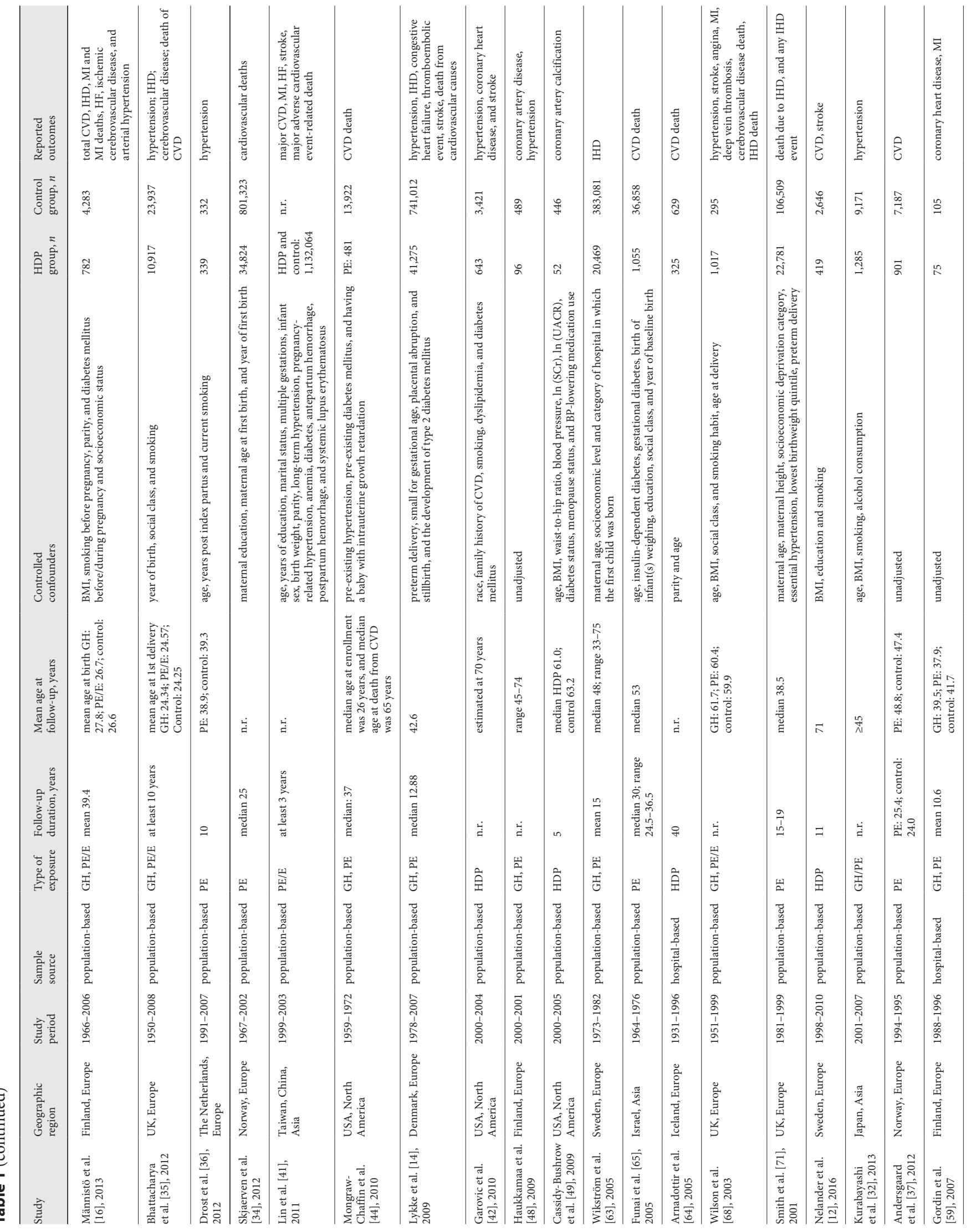




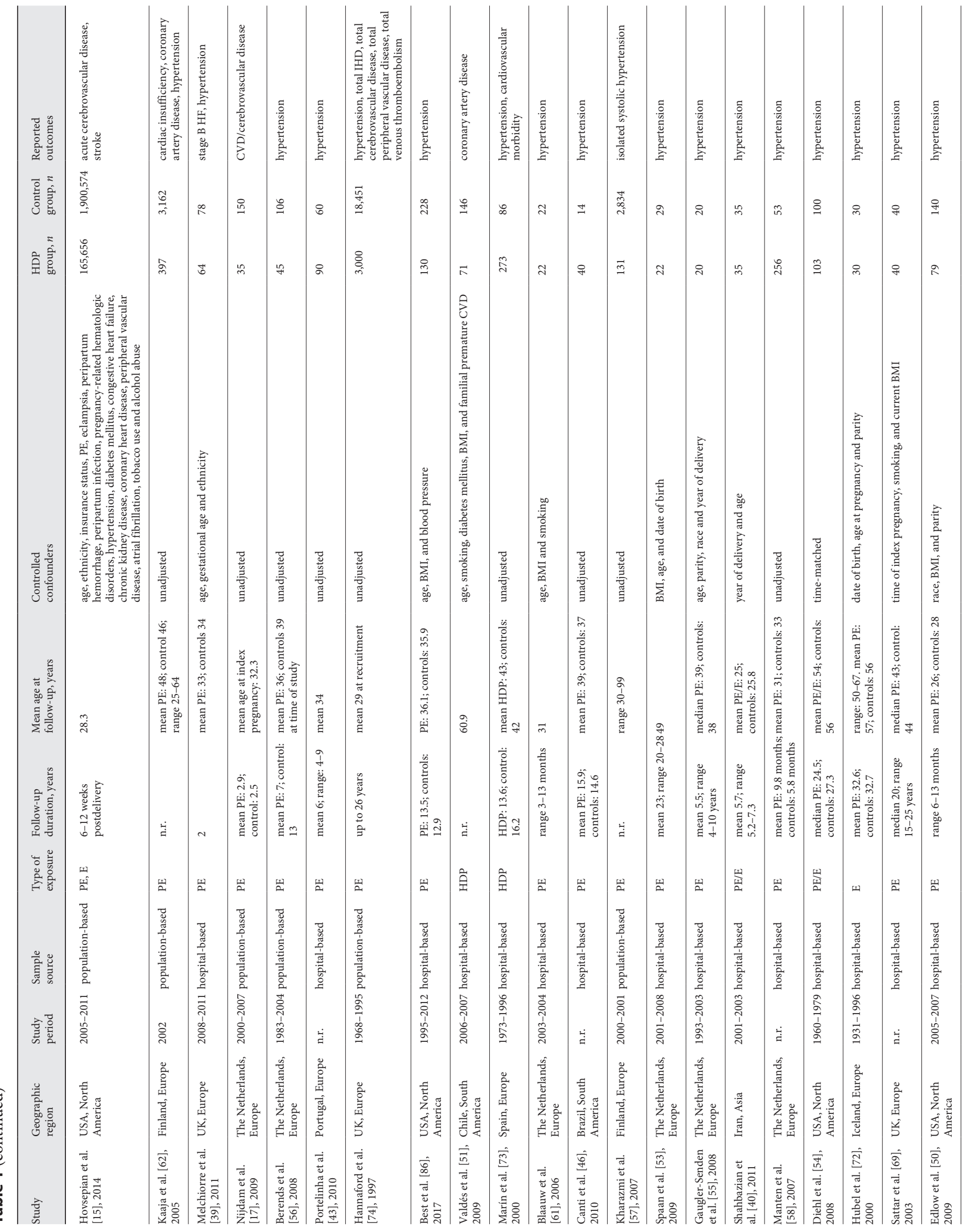




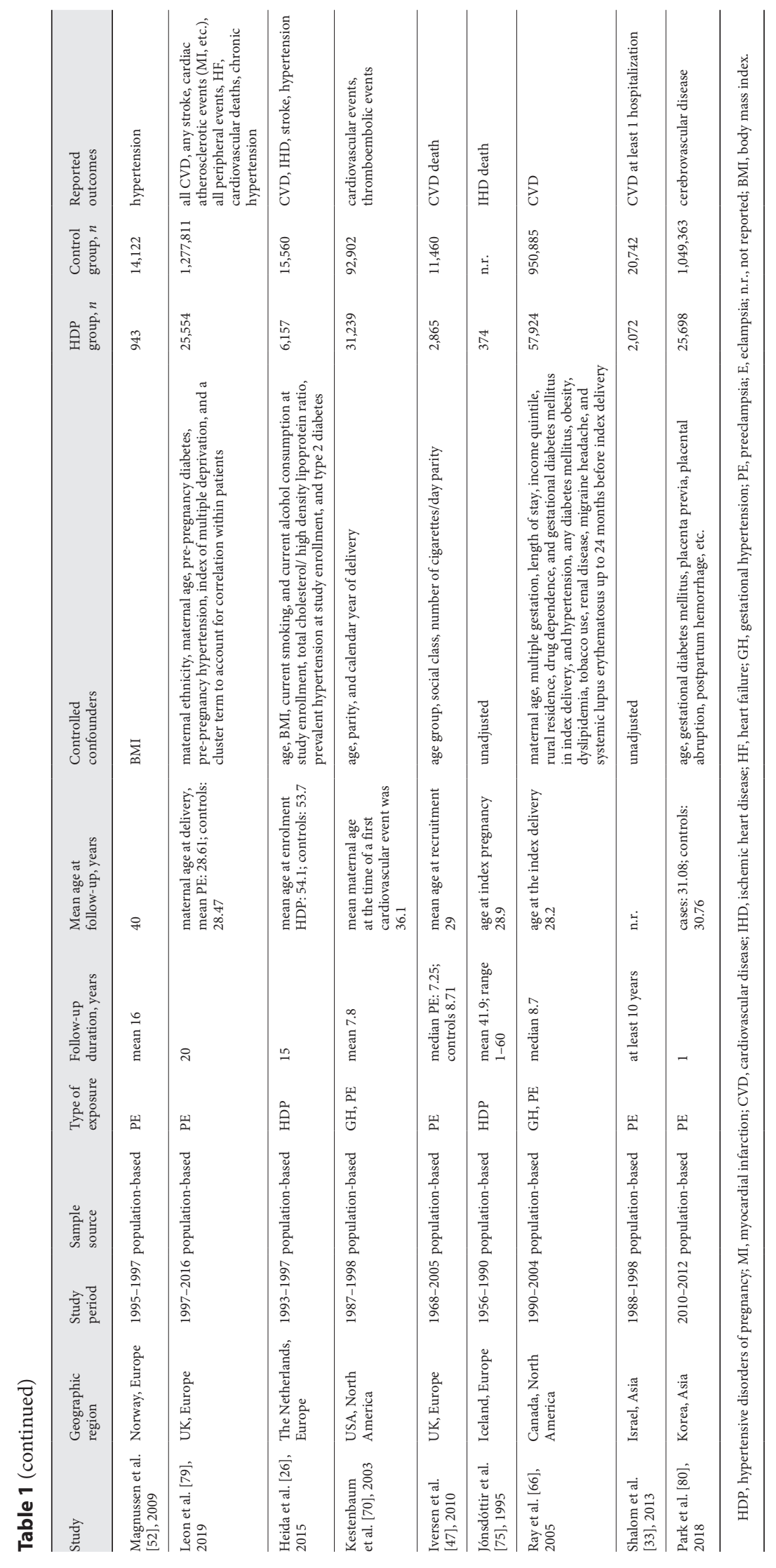


of 73 studies [12, 14-17, 21-88] were considered eligible and were included in this meta-analysis.

Of the 73 observational studies included, 66 were cohort studies and 7 were case-control studies. The characteristics of the 66 cohort studies with a total sample size $>13$ million are shown in Table 1 . There was a large variance in sample sizes $(40-2,066,230)$. The year of publication was between 1995 and 2019, within which nearly $57.6 \%$ (38/66 studies) were published in 2010-2019. Forty studies (60.6\%) were conducted in Europe, $14(21.2 \%)$ in North America, 9 (13.6\%) in Asia, 2 (3.0\%) in South America, and 1 (1.5\%) in Oceania. Studies reported a mean or median age of participants in the range of 25-75 years, whereas median or mean follow-ups ranged from 0 to 42 years. For sample sources, 44 studies $(66.7 \%)$ were population-based, and 22 (33.3\%) were hospital-based. Seventeen studies (25.8\%) did not adjust for any confounder when estimating the risk of CVD associated with HDP, but the remainder (74.2\%) adjusted or matched for age, smoking, or other potential confounders.

The characteristics of the 7 case-control studies with sample sizes ranging from 158 to 3,678 women and published between 2004 and 2019, are shown in Table 2 . Study populations were selected from Europe $(n=3)$, North America $(n=3)$, and Asia $(n=1)$. The age of the participants ranged from 15 to 66 years. For sample sources, 2 studies were population-based and 5 were hospital-based. Adjustments and matches were made in 6 studies.

The quality of the 73 studies included here was evaluated using the NOS as shown in online supplementary Tables 1 and 2 (for all online suppl. material, see www. karger.com/doi/10.1159/000508036). The quality was generally good, as 66 studies (90.4\%) got 6-9 stars. The long-term outcomes reported in the 73 studies were: 43 cases of any CVD, 25 of coronary artery heart disease, 10 of heart failure, 8 of peripheral vascular disease, 14 of stroke, 17 of CVD-related mortality, and 36 of hypertension. Several studies reported more than 1 outcome of interest.

\section{HDP and Risk of Cardiovascular Outcomes}

The risk estimate of any CVD associated with HDP is summarized in Figure 2. The RRs for the association reported by included studies ranged from 0.88 to 13.18. Meta-analytic pooling of these risk estimates yielded a summary RR of 1.80 (95\% CI 1.67-1.94), with substantial heterogeneity $\left(I^{2}=92 \%, p<0.001\right)$. Begg's test did not indicate a potential publication bias $(Z=0.283, p=$ $0.778)$.
The relationships between HDP and coronary artery heart disease, heart failure, peripheral vascular disease, and stroke are summarized in online supplementary Figures 1-4. The overall RR in relation to HDP was 1.66 (95\% CI $1.49-1.84 ; I^{2}=86 \%, p<0.001$ ) for coronary artery heart disease, 2.87 (95\% CI 2.14-3.85; $I^{2}=90 \%, p<$ 0.001 ) for heart failure, 1.60 (95\% CI 1.29-2.00; $I^{2}=76 \%$, $p<0.001)$ for peripheral vascular disease, and $1.72(95 \%$ CI 1.50-1.97; $\left.I^{2}=81 \%, p<0.001\right)$ for stroke. No evidence of publication bias was detected by using Begg's test (coronary artery heart disease: $Z=0.701, p=0.484$; heart failure: $Z=0.626, p=0.531$; peripheral vascular disease: $Z=$ $1.485, p=0.138$; stroke: $Z=1.478, p=0.139)$.

Subgroup analyses for risk of any CVD, coronary artery heart disease, heart failure, peripheral vascular disease, and stroke are shown in online supplementary Table 3. After these analyses were conducted, the variables including geographic region, sample source, type of exposure, and median/mean follow-up time were identified as the relevant heterogeneity moderators for any CVD ( $\chi^{2}$ range: $6.79-22.12$; all $\left.p<0.05\right)$. Notably, in hospital-based studies, the risk estimate of any CVD (2.54, 95\% CI 2.16-2.99) was higher than in studies targeted at the general population $(1.66,95 \%$ CI $1.54-1.78)$. When stratified according to the type of exposure, the pooled risk estimate of any CVD in women with a history with GH (1.64, 95\% CI 1.43-1.89) was lower than that in women with a history of PE (2.07, 95\% CI 1.86-2.30). The risk of developing any CVD associated with a history of HDP was higher in studies with a follow-up time $\leq 10$ years $(2.64,95 \%$ CI $2.15-3.25)$ than in studies with a follow-up time of $10-20$ years $(1.59,95 \%$ CI $1.43-1.75)$ or a follow-up time $\geq 20$ years (1.68, 95\% CI 1.62-1.75). For coronary artery heart disease, variables including geographic region, type of exposure, and median/mean follow-up time partially explained the between-study heterogeneity ( $\chi^{2}$ range: 7.00-23.38; all $p<0.05$ ). The 2 variables geographic region and median/mean follow-up time also partially explained the between-study heterogeneity for heart failure and stroke $\left(\chi^{2}\right.$ range: $13.13-$ 34.62 ; all $p<0.001$ ). Only the sample source was identified as the heterogeneity moderator for peripheral vascular disease $\left(\chi^{2}=9.38, p=0.002\right)$.

\section{HDP and Risk of CVD-Related Mortality}

The risk estimate of CVD-related mortality associated with HDP is summarized in Figure 3. The RR for the association reported in the included studies was in the range of 1.28-5.04. Meta-analytic pooling of these risk estimates yielded a summary RR of 1.78 (95\% CI 1.58-2.00) 


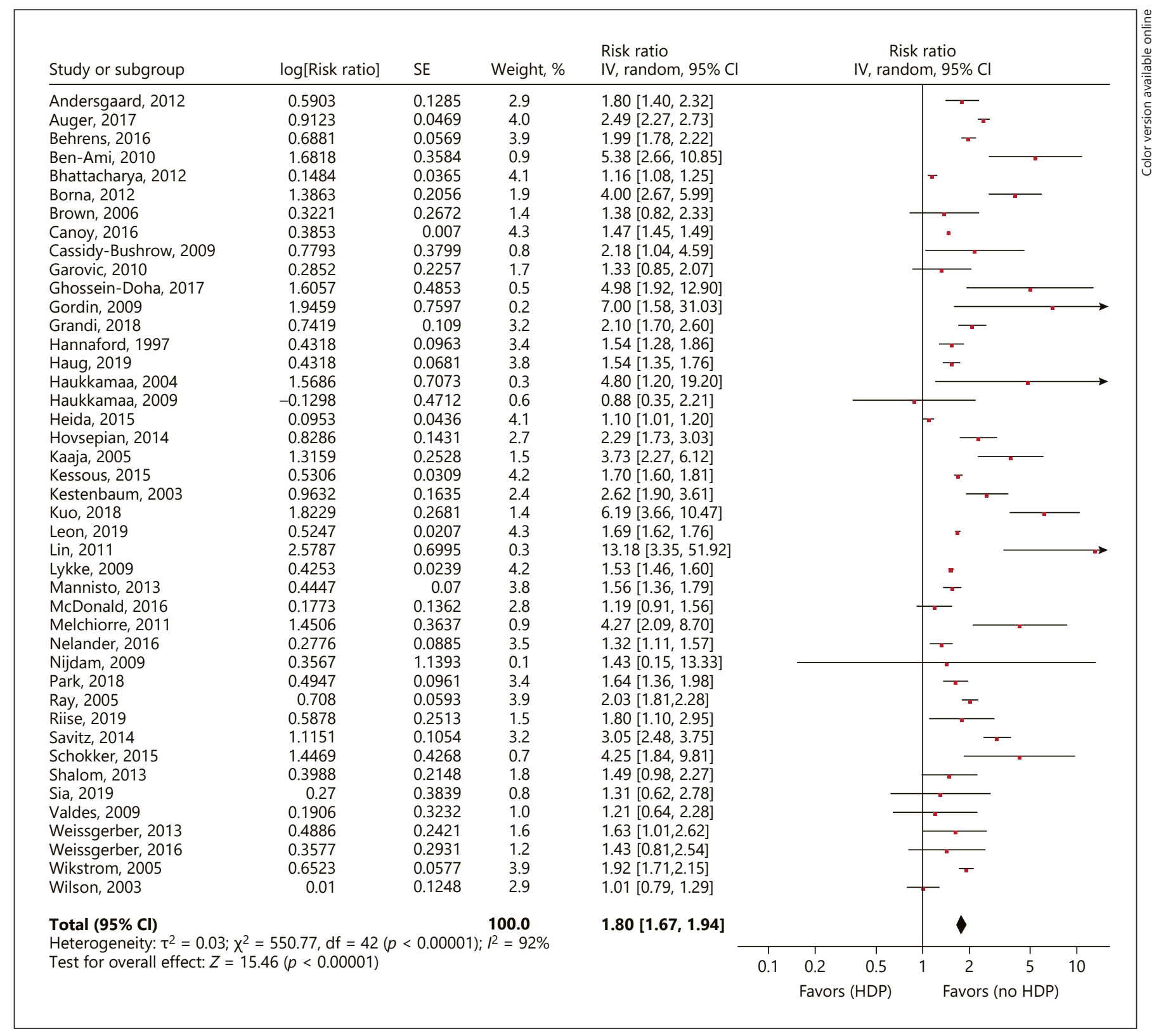

Fig. 2. Risk of any cardiovascular disease associated with hypertensive disorders of pregnancy. CI, confidence interval; IV, inverse variance; SE, standard error.

with substantial heterogeneity $\left(I^{2}=77 \%, p<0.001\right)$. Begg's test did not indicate a potential publication bias $(Z=0.659, p=0.510)$.

Subgroup analyses of risk of CVD-related mortality appear in online supplementary Table 3 . After these analyses, only geographic region was identified as the relevant heterogeneity moderator for CVD-related mortality $\left(\chi^{2}=\right.$ $5.61 ; p=0.018)$. The risk estimate of CVD-related mortality was higher in studies conducted in Asia $(2.63,95 \%$ CI
$1.90-3.65)$ than in those conducted in Europe (1.72, 95\% CI 1.51-1.96).

\section{HDP and Risk of Hypertension}

Online supplementary Figure 5 shows the result from the random-effects model combining the RRs for hypertension in women with a history of HDP. The RRs for the association varied from 1.32 to 23.74. Overall, women with a history of HDP compared to the reference group 


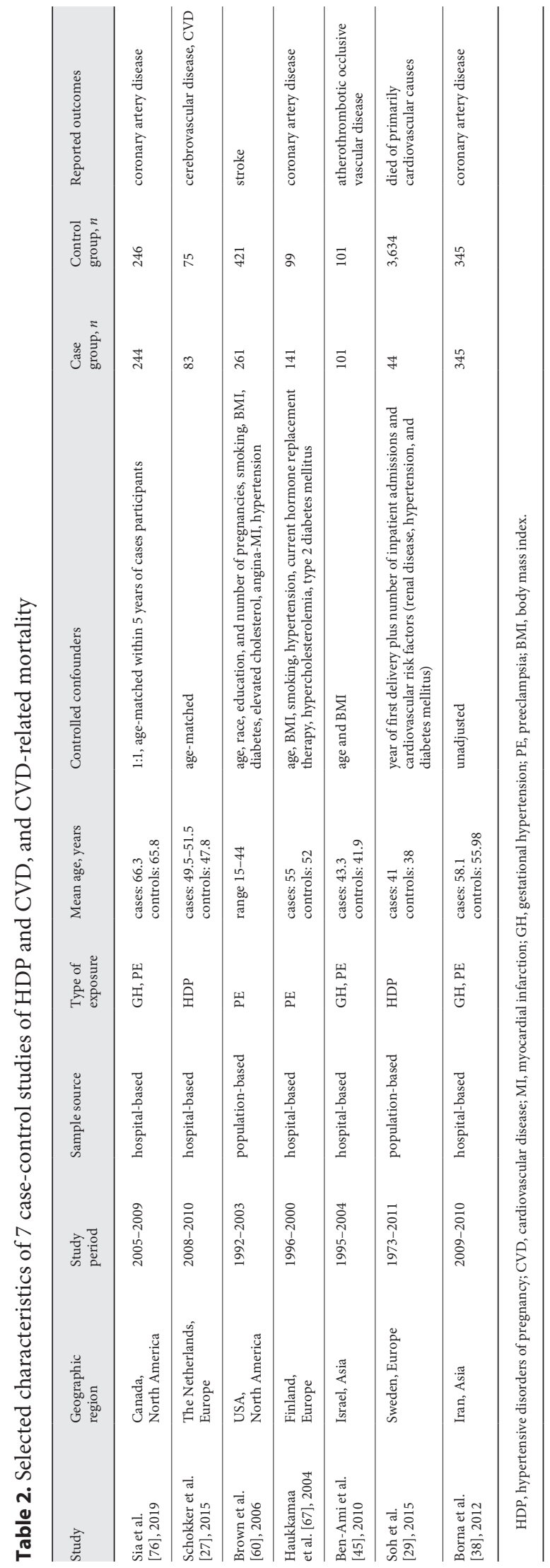

had a significantly higher risk of developing hypertension (RR 3.16 [95\% CI 2.74-3.64]). There was high heterogeneity across studies $\left(I^{2}=98 \%, p<0.001\right)$. Begg's test also did not indicate a potential publication bias $(Z=1.716$, $p=0.086$ ). After subgroup analyses, the variables including sample source and median/mean follow-up time were identified as the relevant heterogeneity moderators for hypertension $\left(\chi^{2}=9.37,12.68\right.$; all $p=0.002$; online suppl. Table 3).

\section{Sensitivity Analyses}

Sensitivity analyses were performed to examine the influence of individual studies on the overall risk estimate for CVD, CVD-related mortality, and hypertension associated with HDP (online suppl. Table 4). Exclusion of any single study did not materially alter the overall combined RR, which ranged from 1.76 (95\% CI 1.64-1.89) to $1.85(1.69-2.03)$ for any CVD, $1.60(1.44-1.77)$ to 1.71 (1.53-1.90) for coronary artery heart disease, 2.59 (1.95$3.44)$ to 3.16 (2.29-4.37) for heart failure, $1.48(1.24-1.77)$ to $1.72(1.44-2.06)$ for peripheral vascular disease, 1.60 (1.41-1.81) to $1.87(1.54-2.28)$ for stroke, 1.72 (1.54$1.92)$ to $1.83(1.62-2.08)$ for CVD-related mortality, and 3.05 (2.64-3.52) to $3.26(2.82-3.77)$ for hypertension. Furthermore, sensitivity analyses were conducted to examine the influence of case-control studies on overall RR (online suppl. Table 5). Results showed that exclusion of case-control studies did not alter the risk estimates for CVD and CVD-related mortality.

\section{Discussion}

In this systematic review and meta-analysis, 73 studies involving $>13$ million women were included. We showed an association of HDP with the long-term risk of developing CVD, CVD-related mortality, and hypertension. The mean risk estimates were 1.80 for CVD, 1.66 for coronary artery heart disease, 2.87 for heart failure, 1.60 for peripheral vascular disease, 1.72 for stroke, 1.78 for CVD-related mortality, and 3.16 for hypertension, when compared with participants without a history of HDP. To the best of our knowledge, this is the most comprehensive metaanalysis to assess the association between HDP and risk of CVD. Our findings supply helpful information to both clinicians and women with HDP and can contribute to the guidelines for the clinical management of HDP in the future.

Five systematic reviews and meta-analysis [89-93] have been previously performed to investigate the asso- 


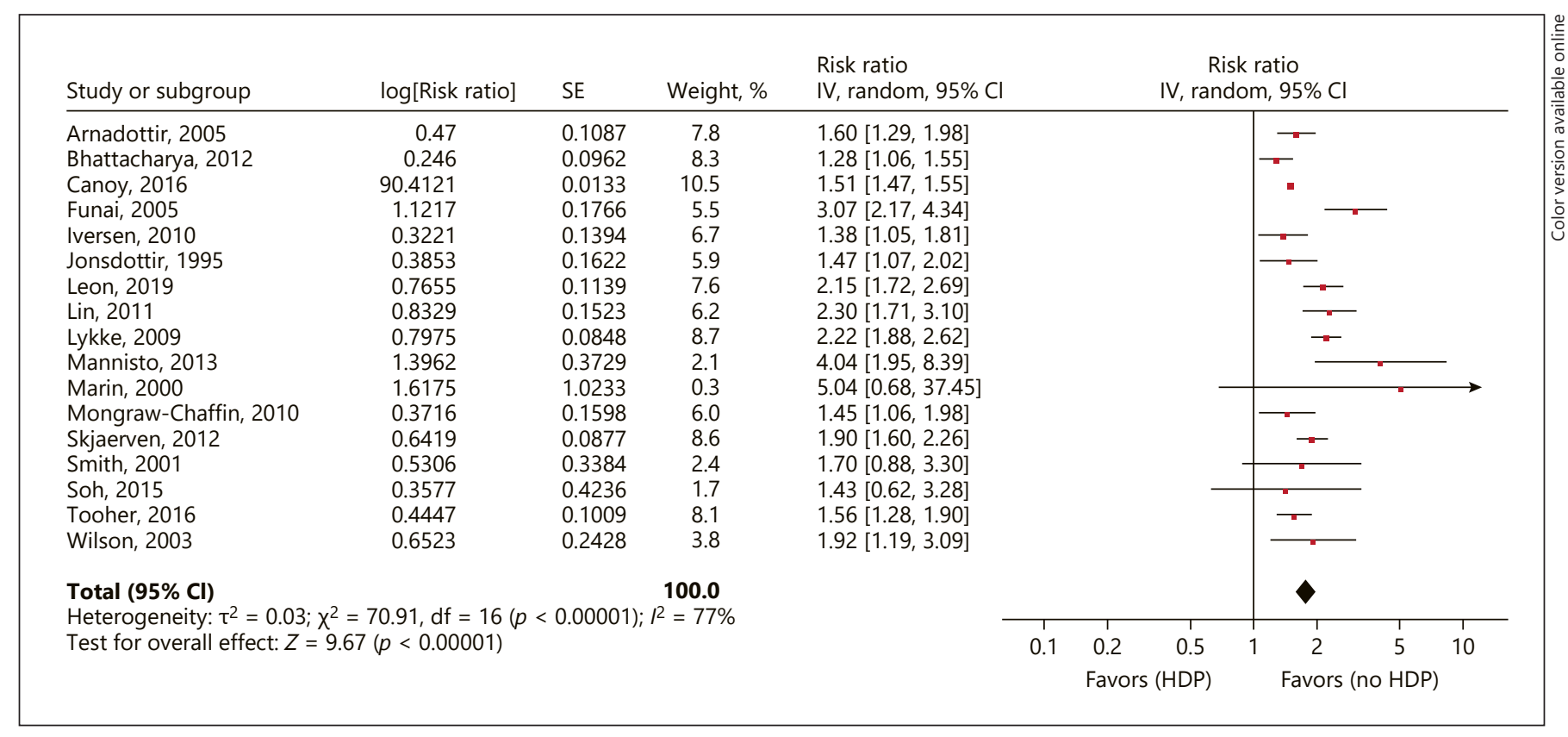

Fig. 3. Risk of cardiovascular-related mortality associated with hypertensive disorders of pregnancy. CI, confidence interval; IV, inverse variance; SE, standard error.

ciation between PE and future CVD, death due to CVD, and hypertension. A recent review, performed by Grandi et al. [94], examined the risk of CVD associated with GH and PE. Although the results of our current meta-analysis are generally in line with these previous reviews, we also provide a contemporary synthesis of the evidence for all HDP with a rigorous assessment of study quality. Given that different types of specific CVD may have different etiologies, it may be conceivable that the risk of developing each specific CVD is inconsistent. Therefore, we combined the risk of specific CVDs in women with HDP, such as coronary artery heart disease, heart failure, etc. Moreover, we synthesized the literature on peripheral vascular disease, which has not been previously performed. By comparison, our risk estimates of CVD associated with $\mathrm{PE}$ were slightly lower than those in a meta-analysis published in 2017 [91], possibly due to the inconsistencies in the included studies. The meta-analysis published in 2017 included 1 study [95] which was not included in our meta-analysis due to the overlap of the study population. Notably, after considering the effects of hypertension in the future coronary heart disease outcome, the link between preeclampsia and future coronary heart disease was no longer statistically significant in 2017. However, the abovementioned meta-analysis was published earlier than 9 large cohort studies from Norway [77, 78], the UK
[21, 79, 83], Denmark [23], the USA [85], Canada [87], and Australia [22], all of which were included in our study.

In our study, the increased risk for all CVD and hypertension was greater at $\leq 10$ years compared with at $>10$ years postpartum. This may be because of a higher absolute risk in the control group during longer follow-up periods (i.e., $>10$ years). Therefore, the reduction in the $\mathrm{RR}$ may be a product of the higher baseline risk. Furthermore, the effect is exacerbated by the small sample size and number of events in the control group reported [39, $73,88]$. Historically, it was thought that $\mathrm{GH}$ is a milder form of PE; our study showed that the risk of developing any CVD in GH was lower than that in PE. However, it is only significantly lower in the outcome of any CVD and coronary artery heart disease. Among other outcomes such as heart failure, stroke, hypertension, and so on, the difference was not statistically significant in the GH and PE groups.

The strength of this study is the large sample size; it consisted of contemporary studies on $>13$ million study participants. This helps to enhance statistical power providing more reliable and precise risk estimates. At the beginning of the study, a comprehensive search strategy was used to identify relevant studies. Moreover, the process including literature retrieval and screening, and data ex- 
traction were performed by 2 reviewers independently. Finally, most of the studies were designed to examine future CVDs as their main outcome $(n=43)$.

One potential limitation of this meta-analysis was the significant heterogeneity across studies for the association between HDP and the risk of developing CVD. This is not surprising, given the different study designs and characteristics of study populations. Fortunately, our subgroup analyses identified several variables associated with the between-study heterogeneity, including geographic region, sample source, type of exposure, and follow-up time. In addition, the variability and complexity of HDP might have contributed to the heterogeneity, given the underlying mechanisms involved in the association between HDP and CVD. However, we were unable to obtain adequate information to test the hypothesis. A second limitation was that significant unmeasured confounding factors may have contributed to the observed association between HDP and CVD. Although most of the studies included here attempted to control for some potential confounding factors, only a few adequately controlled all the conventional cardiovascular risk factors reported in previous studies, such as age, body mass index, gestational diabetes, blood pressure, cholesterol, and family history of CVD. Finally, the duration of follow-up in several of the included studies may not have been sufficient to capture all cardiovascular-related events of interest $[15,30,50,61]$. Last, but not least, according to the previously published studies [91, 93], we used both HRs and ORs to approximate the RRs. Given the lack of information on incidence rates from case-control studies, however, we could not determine the RR from the pooled data. From individual cohort studies, it was suggested that the risk of CVD incidence was low [77-78].

This study demonstrated that all women who present with any of the HDP subtypes are at significant risk of future CVD, CVD-related mortality, and hypertension, when compared with women who remain normotensive during their pregnancy. In view of the burden and impact of CVDs on women in our society, we recommend a detailed cost-benefit analysis to determine the postnatal timing for a screening program in this high-risk population.

\section{Conclusions}

Our meta-analysis reports an increased risk of CVD, CVD-related mortality, and hypertension in women with HDP compared with the reference population. In keeping with current recommendations, our findings highlight the importance of education and lifestyle modifications to reduce risks. Regular monitoring of cardiovascular risk factors in women with a history of HDP is also strongly advised.

\section{Acknowledgments}

The authors would like to thank the editors and reviewers for their suggestions and all colleagues working in the Department of Epidemiology and Health Statistics, Xiangya School of Public Health, Central South University, Hunan, China.

\section{Statement of Ethics}

This systematic review was conducted following the proposed Systematic Reviews and Meta-Analyses (PRISMA) [18] and the Meta-Analysis of Observational Studies in Epidemiology (MOOSE) [19] reporting guidelines.

\section{Conflict of Interest Statement}

The authors have no conflicts of interest to declare.

\section{Funding Sources}

The research was supported by the Major Research and Development Project in Hunan Province (2018SK2062) and the Fundamental Research Funds for the Central Universities of Central South University.

\section{Author Contributions}

L.C., R.W., and T.W. contributed to the conception or design of the work. R.W., T.W., R.G., C.Y., Y.C., X.L., and D.X. contributed to the acquisition, analysis, or interpretation of data for the work. R.W. and T.W. drafted the manuscript. L.C. critically revised the manuscript. All authors gave their final approval and agreed to be accountable for all aspects of work ensuring integrity and accuracy.

\section{References}

1 Fraser A, Nelson SM, Macdonald-Wallis C, Cherry L, Butler E, Sattar N, et al. Associations of pregnancy complications with calculated cardiovascular disease risk and cardiovascular risk factors in middle age: the Avon Longitudinal Study of Parents and Children. Circulation. 2012 Mar;125(11):1367-80.

2 Bridwell M, Handzel E, Hynes M, Jean-Louis R, Fitter D, Hogue C, et al. Hypertensive disorders in pregnancy and maternal and neonatal outcomes in Haiti: The importance of surveillance and data collection. BMC Pregnancy Childbirth. 2019 Jun;19(1):208. 
3 Bakker R, Steegers EA, Hofman A, Jaddoe VW. Blood pressure in different gestational trimesters, fetal growth, and the risk of adverse birth outcomes: the generation R study. Am J Epidemiol. 2011 Oct;174(7):797-806.

4 Basso O, Rasmussen S, Weinberg CR, Wilcox AJ, Irgens LM, Skjaerven R. Trends in fetal and infant survival following preeclampsia. JAMA. 2006 Sep;296(11):1357-62.

5 Ferrazzani S, Luciano R, Garofalo S, D’Andrea V, De Carolis S, De Carolis MP, et al. Neonatal outcome in hypertensive disorders of pregnancy. Early Hum Dev. 2011 Jun;87(6):445-

6 Flenady V, Middleton P, Smith GC, Duke W, Erwich JJ, Khong TY, et al.; Lancet's Stillbirths Series steering committee. Stillbirths: the way forward in high-income countries. Lancet. 2011 May;377(9778):1703-17.

7 Villar J, Carroli G, Wojdyla D, Abalos E, Giordano D, Ba'aqeel H, et al.; World Health Organization Antenatal Care Trial Research Group. Preeclampsia, gestational hypertension and intrauterine growth restriction, related or independent conditions? Am J Obstet Gynecol. 2006 Apr;194(4):921-31.

8 Magee LA, Pels A, Helewa M, Rey E, von Dadelszen P; Canadian Hypertensive Disorders of Pregnancy (HDP) Working Group. Diagnosis, evaluation, and management of the hypertensive disorders of pregnancy. Pregnancy Hypertens. 2014 Apr;4(2):105-45.

9 von Dadelszen P, Magee LA. Preventing deaths due to the hypertensive disorders of pregnancy. Best Pract Res Clin Obstet Gynaecol. 2016 Oct;36:83-102.

10 von Dadelszen P, Magee LA. Pre-eclampsia: an update. Curr Hypertens Rep. 2014 Aug; 16(8):454.

11 Gamble DT, Brikinns B, Myint PK, Bhattacharya S. Hypertensive Disorders of Pregnancy and Subsequent Cardiovascular Disease: Current National and International Guidelines and the Need for Future Research. Front Cardiovasc Med. 2019 May;6(55):55.

12 Nelander M, Cnattingius S, Åkerud H, Wikström J, Pedersen NL, Wikström AK. Pregnancy hypertensive disease and risk of dementia and cardiovascular disease in women aged 65 years or older: a cohort study. BMJ Open. 2016 Jan;6(1):e009880.

13 Smith GN, Pudwell J, Walker M, Wen SW. Ten-year, thirty-year, and lifetime cardiovascular disease risk estimates following a pregnancy complicated by preeclampsia. J Obstet Gynaecol Can. 2012 Sep;34(9):830-5.

14 Lykke JA, Langhoff-Roos J, Sibai BM, Funai EF, Triche EW, Paidas MJ. Hypertensive pregnancy disorders and subsequent cardiovascular morbidity and type 2 diabetes mellitus in the mother. Hypertension. 2009 Jun; 53(6):944-51.

15 Hovsepian DA, Sriram N, Kamel H, Fink ME, Navi BB. Acute cerebrovascular disease occurring after hospital discharge for labor and delivery. Stroke. 2014 Jul;45(7):1947-50.
16 Männistö T, Mendola $P$, Vääräsmäki $M$, Järvelin MR, Hartikainen AL, Pouta A, et al. Elevated blood pressure in pregnancy and subsequent chronic disease risk. Circulation. 2013 Feb;127(6):681-90.

17 Nijdam ME, Timmerman MR, Franx A, Bruinse HW, Numans ME, Grobbee DE, et al. Cardiovascular risk factor assessment after pre-eclampsia in primary care. BMC Fam Pract. 2009 Dec;10(1):77.

18 Moher D, Liberati A, Tetzlaff J, Altman DG PRISMA Group. Preferred reporting items for systematic reviews and meta-analyses: the PRISMA Statement. Open Med. 2009; 3(3):e123-30

19 Stroup DF, Berlin JA, Morton SC, et al. Metaanalysis of observational studies in epidemiology: a proposal for reporting. Meta-analysis Of Observational Studies in Epidemiology (MOOSE) group. JAMA. 2000 Apr;283(15): 2008-12.

20 Borenstein M, Hedges LV, Higgins JP, Rothstein HR. A basic introduction to fixed-effect and random-effects models for meta-analysis. Res Synth Methods. 2010 Apr;1(2):97-111.

21 Canoy D, Cairns BJ, Balkwill A, Wright FL, Khalil A, Beral V, et al.; Million Women Study Collaborators. Hypertension in pregnancy and risk of coronary heart disease and stroke: A prospective study in a large UK cohort. Int J Cardiol. 2016 Nov;222:1012-8.

22 Tooher J, Thornton C, Makris A, Ogle R, Korda A, Horvath J, et al. Hypertension in pregnancy and long-term cardiovascular mortality: a retrospective cohort study. Am J Obstet Gynecol. 2016 Jun;214(6):722.e1-6.

23 Behrens I, Basit S, Lykke JA, Ranthe MF, Wohlfahrt J, Bundgaard $\mathrm{H}$, et al. Association Between Hypertensive Disorders of Pregnancy and Later Risk of Cardiomyopathy. JAMA. 2016 Mar;315(10):1026-33.

24 McDonald EG, Dayan N, Pelletier R, Eisenberg MJ, Pilote L. Premature cardiovascular disease following a history of hypertensive disorder of pregnancy. Int J Cardiol. 2016 Sep; 219:9-13.

25 Weissgerber TL, Turner ST, Mosley TH Jr, Kardia SL, Hanis CL, Milic NM, et al. Hypertension in Pregnancy and Future Cardiovascular Event Risk in Siblings. J Am Soc Nephrol. 2016 Mar;27(3):894-902.

26 Heida KY, Franx A, van Rijn BB, Eijkemans MJ, Boer JM, Verschuren MW, et al. Earlier Age of Onset of Chronic Hypertension and Type 2 Diabetes Mellitus After a Hypertensive Disorder of Pregnancy or Gestational Diabetes Mellitus. Hypertension. 2015 Dec;66(6): 1116-22.

27 Schokker SA, Van Oostwaard MF, Melman EM, Van Kessel JP, Baharoglu MI, Roos YB, et al. Cerebrovascular, cardiovascular and renal hypertensive disease after hypertensive disorders of pregnancy. Pregnancy Hypertens. 2015 Oct;5(4):287-93.
28 Kessous R, Shoham-Vardi I, Pariente G, Sergienko R, Sheiner E. Long-term maternal atherosclerotic morbidity in women with preeclampsia. Heart. 2015 Mar;101(6):442-6.

29 Soh MC, Nelson-Piercy C, Dib F, Westgren M, McCowan L, Pasupathy D. Brief Report: Association between Pregnancy Outcomes and Death from Cardiovascular Causes in Parous Women with Systemic Lupus Erythematosus: A Study Using Swedish Population Registries. Arthritis Rheumatol. 2015 Sep; 67(9):2376-82.

30 Savitz DA, Danilack VA, Elston B, Lipkind HS. Pregnancy-induced hypertension and diabetes and the risk of cardiovascular disease, stroke, and diabetes hospitalization in the year following delivery. Am J Epidemiol. 2014 Jul;180(1):41-4.

31 Weissgerber TL, Turner ST, Bailey KR, Mosley TH Jr, Kardia SL, Wiste HJ, et al. Hypertension in pregnancy is a risk factor for peripheral arterial disease decades after pregnancy. Atherosclerosis. 2013 Jul;229(1): 212-6.

32 Kurabayashi T, Mizunuma H, Kubota T, Kiyohara Y, Nagai K, Hayashi K. Pregnancy-induced hypertension is associated with maternal history and a risk of cardiovascular disease in later life: Japanese cross-sectional study. Maturitas. 2013 Jul;75(3):227-31.

33 Shalom G, Shoham-Vardi I, Sergienko R, Wiznitzer A, Sherf M, Sheiner E. Is preeclampsia a significant risk factor for longterm hospitalizations and morbidity? J Matern Fetal Neonatal Med. 2013 Jan;26(1):135.

34 Skjaerven R, Wilcox AJ, Klungsøyr K, Irgens LM, Vikse BE, Vatten LJ, et al. Cardiovascular mortality after pre-eclampsia in one-child mothers: prospective, population-based cohort study. BMJ. 2012 Nov;345:e7677.

35 Bhattacharya S, Prescott GJ, Iversen L, Campbell DM, Smith WC, Hannaford PC. Hypertensive disorders of pregnancy and future health and mortality: a record linkage study. Pregnancy Hypertens. 2012 Jan;2(1):1-7.

36 Drost JT, Arpaci G, Ottervanger JP, de Boer MJ, van Eyck J, van der Schouw YT, et al. Cardiovascular risk factors in women 10 years post early preeclampsia: the Preeclampsia Risk EValuation in FEMales study (PREVFEM). Eur J Prev Cardiol. 2012 Oct;19(5): 1138-44.

37 Andersgaard AB, Acharya G, Mathiesen EB, Johnsen SH, Straume B, Øian P. Recurrence and long-term maternal health risks of hypertensive disorders of pregnancy: a populationbased study. Am J Obstet Gynecol. 2012 Feb; 206(2):143.e1-8.

38 Borna S, Neamatipoor E, Radman N. Risk of coronary artery disease in women with history of pregnancies complicated by preeclampsia and LBW. J Matern Fetal Neonatal Med. 2012 Jul;25(7):1114-6 
39 Melchiorre K, Sutherland GR, Liberati M, Thilaganathan B. Preeclampsia is associated with persistent postpartum cardiovascular impairment. Hypertension. 2011 Oct;58(4): 709-15.

40 Shahbazian N, Shahbazian H, Ehsanpour A, Aref A, Gharibzadeh S. Hypertension and microalbuminuria 5 years after pregnancies complicated by pre-eclampsia. Iran J Kidney Dis. 2011 Sep;5(5):324-7.

41 Lin YS, Tang CH, Yang CY, Wu LS, Hung ST, Hwa HL, et al. Effect of pre-eclampsia-eclampsia on major cardiovascular events among peripartum women in Taiwan. Am J Cardiol. 2011 Jan;107(2):325-30.

42 Garovic VD, Bailey KR, Boerwinkle E, Hunt SC, Weder AB, Curb D, et al. Hypertension in pregnancy as a risk factor for cardiovascular disease later in life. J Hypertens. 2010 Apr; 28(4):826-33.

43 Portelinha A, Belo L, Cerdeira AS, Braga J, Tejera E, Pinto F, et al. Lipid levels including oxidized LDL in women with history of preeclampsia. Hypertens Pregnancy. 2010 Jan; 29(1):93-100.

44 Mongraw-Chaffin ML, Cirillo PM, Cohn BA Preeclampsia and cardiovascular disease death: prospective evidence from the child health and development studies cohort. Hypertension. 2010 Jul;56(1):166-71.

45 Ben-Ami S, Oron G, Ben-Haroush A, Blickstein D, Hod M, Bar J. Primary atherothrombotic occlusive vascular events in premenopausal women with history of adverse pregnancy outcome. Thromb Res. 2010 Feb; 125(2):124-7.

46 Canti IC, Komlós M, Martins-Costa SH, Ramos JG, Capp E, Corleta H. Risk factors for cardiovascular disease ten years after preeclampsia. Sao Paulo Med J. 2010 Jan;128(1): 10-3.

47 Iversen L, Hannaford PC. Toxaemia of pregnancy and risk of mortality in later life: evidence from the Royal College of General Practitioners' Oral Contraception Study. Hypertens Pregnancy. 2010 Jan;29(2):180-97.

48 Haukkamaa L, Moilanen L, Kattainen A, Luoto R, Kahonen M, Leinonen M, et al. Pre-eclampsia is a risk factor of carotid artery atherosclerosis. Cerebrovasc Dis. 2009;27(6): 599-607.

49 Cassidy-Bushrow AE, Bielak LF, Rule AD, Sheedy PF 2nd, Turner ST, Garovic VD, et al. Hypertension during pregnancy is associated with coronary artery calcium independent of renal function. J Womens Health (Larchmt). 2009 Oct;18(10):1709-16.

50 Edlow AG, Srinivas SK, Elovitz MA. Investigating the risk of hypertension shortly after pregnancies complicated by preeclampsia. Am J Obstet Gynecol. 2009 May;200(5):e602.

51 Valdés G, Quezada F, Marchant E, von Schultzendorff A, Morán S, Padilla O, et al. Association of remote hypertension in pregnancy with coronary artery disease: a case-control study. Hypertension. 2009 Apr;53(4):733-8.
52 Magnussen EB, Vatten LJ, Smith GD, Romundstad PR. Hypertensive disorders in pregnancy and subsequently measured cardiovascular risk factors. Obstet Gynecol. 2009 Nov;114(5):961-70.

53 Spaan JJ, Ekhart T, Spaanderman ME, Peeters LL. Remote hemodynamics and renal function in formerly preeclamptic women. Obstet Gynecol. 2009 Apr;113(4):853-9.

54 Diehl CL, Brost BC, Hogan MC, Elesber AA, Offord KP, Turner ST, et al. Preeclampsia as a risk factor for cardiovascular disease later in life: validation of a preeclampsia questionnaire. Am J Obstet Gynecol. 2008 May; 198(5):e11-3

55 Gaugler-Senden IP, Berends AL, de Groot CJ, Steegers EA. Severe, very early onset preeclampsia: subsequent pregnancies and future parental cardiovascular health. Eur J Obstet Gynecol Reprod Biol. 2008 Oct;140(2): 171-7.

56 Berends AL, de Groot CJ, Sijbrands EJ, Sie MP, Benneheij SH, Pal R, et al. Shared constitutional risks for maternal vascular-related pregnancy complications and future cardiovascular disease. Hypertension. 2008 Apr; 51(4):1034-41.

57 Kharazmi E, Kaaja R, Fallah M, Luoto R. Pregnancy-related factors and the risk of isolated systolic hypertension. Blood Press. 2007; 16(1):50-5.

58 Manten GT, Sikkema MJ, Voorbij HA, Visser $\mathrm{GH}$, Bruinse HW, Franx A. Risk factors for cardiovascular disease in women with a history of pregnancy complicated by preeclampsia or intrauterine growth restriction. Hypertens Pregnancy. 2007;26(1):39-50.

59 Gordin D, Hiilesmaa V, Fagerudd J, Rönnback M, Forsblom C, Kaaja R, et al.; FinnDiane Study Group. Pre-eclampsia but not pregnancy-induced hypertension is a risk factor for diabetic nephropathy in type 1 diabetic women. Diabetologia. 2007 Mar;50(3):51622.

60 Brown DW, Dueker N, Jamieson DJ, Cole JW, Wozniak MA, Stern BJ, et al. Preeclampsia and the risk of ischemic stroke among young women: results from the Stroke Prevention in Young Women Study. Stroke. 2006 Apr; 37(4):1055-9.

61 Blaauw J, van Pampus MG, Van Doormaal JJ, Fokkema MR, Fidler V, Smit AJ, et al. Increased intima-media thickness after earlyonset preeclampsia. Obstet Gynecol. 2006 Jun;107(6):1345-51.

62 Kaaja R, Kinnunen T, Luoto R. Regional differences in the prevalence of pre-eclampsia in relation to the risk factors for coronary artery disease in women in Finland. Eur Heart J. 2005 Jan;26(1):44-50.

63 Wikström AK, Haglund B, Olovsson M, Lindeberg SN. The risk of maternal ischaemic heart disease after gestational hypertensive disease. BJOG. 2005 Nov;112(11):1486-91.
64 Arnadottir GA, Geirsson RT, Arngrimsson R, Jonsdottir LS, Olafsson O. Cardiovascular death in women who had hypertension in pregnancy: a case-control study. BJOG. 2005 Mar;112(3):286-92.

65 Funai EF, Friedlander Y, Paltiel O, Tiram E, Xue X, Deutsch L, et al. Long-term mortality after preeclampsia. Epidemiology. 2005 Mar; 16(2):206-15.

66 Ray JG, Vermeulen MJ, Schull MJ, Redelmeier DA. Cardiovascular health after maternal placental syndromes (CHAMPS): population-based retrospective cohort study. Lancet. 2005 Nov;366(9499):1797-803.

67 Haukkamaa L, Salminen M, Laivuori H, Leinonen H, Hiilesmaa V, Kaaja R. Risk for subsequent coronary artery disease after preeclampsia. Am J Cardiol. 2004 Mar;93(6): 805-8.

68 Wilson BJ, Watson MS, Prescott GJ, Sunderland S, Campbell DM, Hannaford P, et al. Hypertensive diseases of pregnancy and risk of hypertension and stroke in later life: results from cohort study. BMJ. 2003 Apr;326(7394): 845.

69 Sattar N, Ramsay J, Crawford L, Cheyne H, Greer IA. Classic and novel risk factor parameters in women with a history of preeclampsia. Hypertension. 2003 Jul;42(1):39-42.

70 Kestenbaum B, Seliger SL, Easterling TR, Gillen DL, Critchlow CW, Stehman-Breen CO, et al. Cardiovascular and thromboembolic events following hypertensive pregnancy. Am J Kidney Dis. 2003 Nov;42(5):982-9.

71 Smith GC, Pell JP, Walsh D. Pregnancy complications and maternal risk of ischaemic heart disease: a retrospective cohort study of 129,290 births. Lancet. 2001 Jun;357(9273):2002-6.

72 Hubel CA, Snaedal S, Ness RB, Weissfeld LA, Geirsson RT, Roberts JM, et al. Dyslipoproteinaemia in postmenopausal women with a history of eclampsia. BJOG. 2000 Jun;107(6): 776-84.

73 Marín R, Gorostidi M, Portal CG, Sánchez M, Sánchez E, Alvarez J. Long-term prognosis of hypertension in pregnancy. Hypertens Pregnancy. 2000;19(2):199-209.

74 Hannaford P, Ferry S, Hirsch S. Cardiovascular sequelae of toxaemia of pregnancy. Heart. 1997 Feb;77(2):154-8.

75 Jónsdóttir LS, Arngrímsson R, Geirsson RT, Sigvaldason H, Sigfússon N. Death rates from ischemic heart disease in women with a history of hypertension in pregnancy. Acta Obstet Gynecol Scand. 1995 Nov;74(10):772-6.

76 Sia WW, Pertman SM, Yan RM, Tsuyuki RT. Are Preeclampsia and Adverse Obstetrical Outcomes Predictors of Cardiovascular Disease? A Case-Control Study of Women with Heart Disease. J Obstet Gynaecol Can. 2019 Dec;41(12):1760-7.

77 Riise HK, Sulo G, Tell GS, Igland J, Egeland G, Nygard O, et al. Hypertensive pregnancy disorders increase the risk of maternal cardiovascular disease after adjustment for cardiovascular risk factors. Int J Cardiol. 2019 May; 282:81-7. 
78 Haug EB, Horn J, Markovitz AR, Fraser A, Klykken B, Dalen H, et al. Association of Conventional Cardiovascular Risk Factors with Cardiovascular Disease after Hypertensive Disorders of Pregnancy: Analysis of the Nord-Trøndelag Health Study. JAMA Cardiol. 2019 Jul;4(7):628-35.

79 Leon LJ, McCarthy FP, Direk K, GonzalezIzquierdo A, Prieto-Merino D, Casas JP, et al. Preeclampsia and Cardiovascular Disease in a Large UK Pregnancy Cohort of Linked Electronic Health Records: A CALIBER Study. Circulation. 2019 Sep;140(13):1050-60.

80 Park Y, Cho GJ, Kim LY, Lee TS, Oh MJ, Kim YH. Preeclampsia Increases the Incidence of Postpartum Cerebrovascular Disease in Korean Population. J Korean Med Sci. 2018 Feb; 33(6):e35.

81 Mito A, Arata N, Qiu D, Sakamoto N, Murashima A, Ichihara A, et al. Hypertensive disorders of pregnancy: a strong risk factor for subsequent hypertension 5 years after delivery. Hypertens Res. 2018 Feb;41(2):141-6.

82 Kuo YL, Chan TF, Wu CY, Ker CR, Tu HP. Preeclampsia-eclampsia and future cardiovascular risk among women in Taiwan. Taiwan J Obstet Gynecol. 2018 Jun;57(3):364-9.

83 Grandi SM, Reynier P, Platt RW, Basso O, Filion $\mathrm{KB}$. The timing of onset of hypertensive disorders in pregnancy and the risk of incident hypertension and cardiovascular disease. Int J Cardiol. 2018 Nov;270:273-5.
84 Bergen NE, Schalekamp-Timmermans S, Roos-Hesselink J, Roeters van Lennep JE, Jaddoe VV, Steegers EA. Hypertensive disorders of pregnancy and subsequent maternal cardiovascular health. Eur J Epidemiol. 2018 Aug;33(8):763-71.

85 Stuart JJ, Tanz LJ, Missmer SA, Rimm EB, Spiegelman D, James-Todd TM, et al. Hypertensive Disorders of Pregnancy and Maternal Cardiovascular Disease Risk Factor Development: An Observational Cohort Study. Ann Intern Med. 2018 Aug;169(4):224-32.

86 Best LG, Lunday L, Webster E, Falcon GR, Beal JR. Pre-eclampsia and risk of subsequent hypertension: in an American Indian population. Hypertens Pregnancy. 2017 May;36(2): 131-7.

87 Auger N, Fraser WD, Schnitzer M, Leduc L, Healy-Profitós J, Paradis G. Recurrent preeclampsia and subsequent cardiovascular risk. Heart. 2017 Feb;103(3):235-43.

88 Ghossein-Doha C, van Neer J, Wissink B, Breetveld NM, de Windt LJ, van Dijk AP, et al. Pre-eclampsia: an important risk factor for asymptomatic heart failure. Ultrasound $\mathrm{Ob}$ stet Gynecol. 2017 Jan;49(1):143-9.

89 Brown MC, Best KE, Pearce MS, Waugh J, Robson SC, Bell R. Cardiovascular disease risk in women with pre-eclampsia: systematic review and meta-analysis. Eur J Epidemiol. 2013 Jan;28(1):1-19.
90 McDonald SD, Malinowski A, Zhou Q, Yusuf S, Devereaux PJ. Cardiovascular sequelae of preeclampsia/eclampsia: a systematic review and meta-analyses. Am Heart J. 2008 Nov; 156(5):918-30.

91 Wu P, Haththotuwa R, Kwok CS, Babu A, Kotronias RA, Rushton C, et al. Preeclampsia and Future Cardiovascular Health: A Systematic Review and Meta-Analysis. Circ Cardiovasc Qual Outcomes. 2017 Feb;10(2): pii:e003497.

92 Bellamy L, Casas JP, Hingorani AD, Williams DJ. Pre-eclampsia and risk of cardiovascular disease and cancer in later life: systematic review and meta-analysis. BMJ. 2007 Nov; 335(7627):974-7.

93 Brouwers L, van der Meiden-van Roest AJ, Savelkoul C, Vogelvang TE, Lely AT, Franx A, et al. Recurrence of pre-eclampsia and the risk of future hypertension and cardiovascular disease: a systematic review and meta-analysis. BJOG. 2018 Dec;125(13):1642-54.

94 Grandi SM, Filion KB, Yoon S, Ayele HT, Doyle CM, Hutcheon JA, et al. Cardiovascular Disease-Related Morbidity and Mortality in Women with a History of Pregnancy Complications. Circulation. 2019 Feb; 139(8): 1069-79.

95 Grandi SM, Vallée-Pouliot K, Eberg M, Platt RW, Arel R, Filion KB. Hypertensive disorders in pregnancy and the risk of incident cardiovascular disease. Circulation. 2015; 131:AMP20. 